\title{
Informating Smart Cities Governance? Let Us First Understand the Atoms!
}

\author{
Alois Paulin ${ }^{1}$ \\ Received: 11 September 2015 / Accepted: 8 March 2016 / \\ Published online: 6 April 2016 \\ (C) The Author(s) 2016. This article is published with open access at Springerlink.com
}

\begin{abstract}
This paper discusses the atomic factors that make up governance with a focus on Smart Cities informatability. The guiding question is whether or not, or how, respectively, governance can be informated; informatization is defined as the ability of systems to be steered/controlled/created from within the digital dimension by means of software tools and applications. The disciplinary theories of Downs (public choice theory), Jellinek (Statuslehre), and Hohfeld (fundamental legal conceptions) are confronted with the abilities of modern information and communication technology in the quest to apply them for informatization of governance. It is found that the atomic components of governance identified by these theories cannot be directly informated; there is however indication for their indirect informatability, which is discussed further. The vision of a society in which governance is informated is presented after the discussion to aid in understanding of the context, its potentials, and the relevance of basic research for sustainable governance evolution.
\end{abstract}

Keywords e-Governance - Jural eligibilities · Informating governance · Beyond bureaucracy

\section{Introduction}

Born and raised as a marketing term in mid-' 90 s (and in a second wave in the late '00s) (Söderström et al. 2014), the "Smart City" remains a reference to a set of broad concepts referring to trends and transformations in the context of modern urban spaces. It partly, but not exclusively (Söderström et al. 2014; Anthopoulos 2015), refers to the utilization of ICT to introduce transformations and enable new value chains on the government to citizen $(\mathrm{G} \rightarrow \mathrm{C})$ relation between the city as a public sphere and the

Alois Paulin

alois@apaulin.com

1 Vienna University of Technology-Faculty of Informatics, Favoritenstr. 9-11, 1040 Vienna, Austria 
citizens as its customers. Amongst the manifold dimensions of the Smart City concept (Anthopoulos and Fitsilis 2013), the provision of e-governance and e-democracy features on city-level are relevant objectives. As such, Smart City research and development $(\mathrm{R} \& \mathrm{D})$ activities overlap with the broader domain of e-governance research, whose objective is the computerization and informatization of governance to an extent where latter is hoped to become transformed by means of ICT.

R\&D and marketing activities of Smart Cities assume cities as homogeneous entities, which provide services to their citizens; based on this premise, IBM's Smarter Cites campaign (a prominent and potent driver of the Smart City concept) projects the city as a coherent system-of-systems, whose social functions can be automated and orchestrated through a central information system, like e.g. IBM's Intelligent Operations Center (Söderström et al. 2014).

The assumption of a coherent provider of urban social functions however is not aligned with the inherently participative and evolutive nature of the democratic public sphere (the res publica), where heterogeneous stakeholders dynamically interact and participatively shape their habitat. While one may model "the city" as a coherent entity for sake of political or empirical rhetoric, or see the municipal government as a business client respectively, the assumption of a monolithic entity does not serve as a feasible basis for sustainable technological progress. Rather, public domain action (i.e. the provision of social services, public policy making, collaborative decision-making, etc.) is realized by a constantly evolving landscape of heterogeneous stakeholders with often competing ambitions (cf. Downs 1967).

The evolutionary and multi-stakeholder nature of public domain action impacts the ability to use traditional software engineering approaches in creating artefacts to automate, or informate, respectively, public domain action that would be able to sustain for future generations (Paulin 2015).

In search for a generation-spanning base for informating public domain action, this article aims to find which atomic "nuts and bolts" of governance can be abstracted into the digital world of informatics to serve as a foundation for a generic (i.e. not constrained to a set of predefined use-cases or use-case categories) communicational platform for empowering, steering and supervising public domain action. Leaving visionary ideas of the use of artificial intelligence/government automation or machine-moderated policymaking deliberately aside, this article aims to contribute to following research questions:

\section{R1: What are the atomic factors of governance?}

R2: Can the atomic factors from R1 be informated?

To address R1, we shall deploy the instrument of an informed argument to elaborate an overview of knowledge on how public domain empowerment, action, and control are established. We shall restrict the exploration to timeless features of public domain action, rather than focusing on a particular epoch or government system. Question R2 shall be explored by discussing if, and how, respectively, the results from R1 can be abstracted into the digital realm by means of know technology.

This article is structured as follows: section 2 provides a general overview over the problem domain of governance informatability and defines the theoretical constraints. As part of this section, the paper aims to drill towards the core principles and constraints of governance, addressing question R1 in section 2.1. Section 3 addresses 
R2 by analysing and discussing the informatability of the outcome from R1. Section 4 offers a vision of the informated Smart City as a co-productive habitat; section 5 concludes.

\section{Intended Contribution to Smart City Research}

This paper's main aim is to open up a novel discussion on the informatability of governance, as a basic prerequisite to enable research and development towards sustainable information systems, standards, and approaches to governance informatization. Considering this, it deliberately avoids any discussion on the effects ICT had so far on urban spaces, city/town-level public administration, and other systems/functions of modern cities. From avoiding such discussion and deliberately assuming a (not necessarily, but potentially, blank-slate) context in which informated governance is introduced to society without the constraints of the legacy of an existing institutional/administrative framework, the expected gain is knowledge on how to "reinvent government" (O'Reilly in (2010)) for the digital age. Likewise, in the context of this discussion any speculation about potential benefit/detriment of governance informatization on humanity shall be avoided, in order not to lose the focus of the treatise.

As such, this paper does not aim to contribute to improving/transforming the performance or working conditions of modern government agencies, but rather aims exclusively on providing a theoretical contribution for further research towards digital era governance.

The relevance for the Smart City context of these questions lies in the ability to provide a basic understanding for research towards a generic, common platform on top of which modular systems of governance technologies can build. Modular, generic technology can then be bundled to technology stacks (existing examples are e.g. the Web, or Java), which allow for the emergence of virtual ecosystems in which scholars, engineers, and consumer-edge stakeholders can share applied knowledge, co-create and naturally evolve informated governance. From adequately informated governance, added value is expected to emerge, similar to the transformational effects ICTs had on other areas of human interaction.

\section{Background}

Smart City governance is sharing challenges and goals with general electronic governance objectives, with specific focus on the governance of the urban public space. With typical application scenarios and research endeavours centring on mass-scale applicative contexts such as traffic management, urban planning, public transport, communal service provisioning, etc., crucial implications of political spaces are often marginalized and taken out of consideration in scientific and industrial research. As has been argued (Paulin 2015), ignoring political and jural implications can have severe adverse effects on the sustainability of technical artefacts, in terms of premature project failure, vendor lock-in situations, and the violation of democratic principles.

The density of population in urban spaces implies the need for laying special care on adhering to democratic principles in public domain governance in order to prevent 
unnecessary tensions from emerging. Core features of democratic spaces, such as transparency, participation, and collaborative decision-making need thus to be taken into consideration when planning and developing informated governance systems.

Using concepts as defined herein below, this section shall analyse the implications for governance informatability and search for atomic elements of governance, in order to respond to the first research question.

\section{Governance}

"Governance" is a term that bears significant ambiguity and has heterogeneous meaning in different contexts (Bevir 2009, pt. I). For sake of clarity, this term shall be used in the context of the present discussion to denote the set of all public-domain (i.e., nonmarket) social functions, including functions such as collaborative decisionmaking (e.g. the passing of a new law or policies), dispute resolution (the function of judges), and the empowerment and activities of authority (e.g. the many heterogeneous functions of the various levels of public administrations).

With this in mind, exploration of governance shall be limited to the analysis of its atomic elements and shall deliberately avoid discussing humanistic implications of such. Thus, the discussion is focused on how governance can be seen in strictly technical terms, rather than what it ought to be in order to meet expectations of various stakeholders.

\section{Artefact}

This article shall follow the notion of the word "artefact" as used in the domain of design science information systems research, where it refers to "constructs (vocabulary and symbols), models (abstractions and representations), methods (algorithms and practices), and instantiations (implemented and prototype systems)" (Hevner et al. 2004). The artefact is thus a describable and isolatable component that can be described on its own and can be used as part of a system.

\section{Informating/Informatable}

"Informating" shall be used to denote the action of modelling real-world artefacts into virtualized representations for their use in the domain of software systems. "Informating", correspondingly, shall denote the ability of an artefact to be informated.

"Informating" has been used already by Zuboff (1988) and carried there a similar meaning. Informating something in this discussion does not stringently imply using such artefact in an automated context, nor using it for computation; the result of informating an artefact is rather making this artefact representable in the digital realm - the so informated something can, but needs not, later be used for computation, automation, or computerization. A scientific article obtained through the web is, in this context, an informated artefact, but has not been automated, nor computed, despite that the process of typing, storing, downloading, and rendering it on one's screen heavily relied on and contained elements of both automation and computation. 


\section{Informating Governance: a Wicked Problem?}

If a visual artist uses IT to craft its creations, he will use software tools, which aid him in creating informated art. This art, though rendered to the human observer in form of a picture, will in reality be a complex multidimensional set of informated strokes, their attributes, and instructions to the rendering system how to present them to the consuming presentation device. Latter might be the computer screen or the printing system, or any other consuming device that has been designed to handle the inputted set of informated entities without regard to whether or not it has been designed to adhere to their semantics as the human author of the informated art intended them to be. Scalable Vector Graphics (SVG) images for example are such that they can be seen as picturesstatic, interactive, or moving, or edited as text.

Ever since in human history, man-crafted visual arts have been all about arranging material (paint, pencil strokes, fibre, etc.) to form the intended result. IT however has enabled to informate the atomic elements from which art is composed and thus transformed this domain in an unprecedented way. Production- and service-oriented commercial activities have experienced revolutionary transformation due to informatization — speed, precision and cost was radically optimized, providing added value beyond what was possible till then.

If a banker transfers funds across the ocean, the informated credits are transferred as sets of informated numbers and their attributes, which together form a system representing instructions to achieve the effect intended. Unlike the above-outlined revolution of the various fields of production, informating credits and their transfer is a legacy from our past generations - think of bank checks, telegraphic transfer, and the age-old concept of currency as such. Nevertheless, modern ICTs equally brought an unprecedented boost to the evolution of credit transfer up till the point where global transfer systems enable new experiences in travel, commerce, etc.

Informatization has brought revolutionary transformative effects to nearly all aspects of human interaction in society, often eliminating the necessity for human action in processes of production, trade, entertainment, knowledge acquisition and dissemination, etc....

...But what were the effects modern ICT had on governance? The introduction of ICTs in governance, Paulin (2015) argues, had no transforming effect on the domain, but rather contributed to strengthening existing patterns of conduct, leading to increasing overall cost of governance, while leaving the utility of state-delivered social functions at a stagnating level. Aside from the lack of perceivable optimization on the macro-level, looking closer at individual technologies, the approaches chosen for the construction of individual technical systems for governance have been found (ibid.) to be inappropriate due to the political nature of the domain, and the thus perpetually pending danger of unpredictable context change that renders solution-focused technical artefacts obsolete. Another consideration why systems for governance are constructed using inadequate approaches has been offered by Lenk (2012), who points at the differences between private-sector business process reengineering and the particularities of decision-making in the context of the public administration. In latter, he argues, "many decisions are made at the shop floor level every day", while in former processes can be structured upfront, as such executed, and hence, automated. 
In trade and manufacturing global technical platforms such as the SWIFT (intl. financial transfers) system, or global distribution systems like the Amadeus computer reservations system for travel ticket reservation gave rise to whole new economies. The business of providing social functions by means of governance, on the other hand, has no such infrastructure available around which it could centre its activities and from which new added value could emerge.

Focusing on public administration, which plays a major role in the governance domain as such, Lenk (ibid.) divides governance processes into three coarse categories:

(a) Recurrent and well-structured processes (e.g. allocating kindergarten spaces or parking rights) which give little discretion to the involved;

(b) Individualized decision making, which is determined by strong interaction between stakeholders, whereby the flow of interaction through the process is often not foreseeable in detail;

(c) Negotiation processes, which are highly complex situations with no foreseeable structure.

Informating is feasible as long as the artefact one wants to informate can be abstracted in such way that its informated (virtualised) representation can cause real world effect. Such is possible with informated brush strokes, informated currency, informated airplane tickets, informated industrial parts, etc. In Lenk's categories, artefacts from category "a" could easily be informated, was it not for Paulin's (2015) sustainability concerns; artefacts from that category can further be, to some extent, automated, as is such the case in modern e-government systems that automate the processing of tax returns, car registration, and similar routine governance processes. Category "b", due to lack of structure and foreseeability, cannot be automated, but could, to some extent, be informated, provided that the object of the decision-making process would be informatable, and stages of the process could be appropriately defined - the thus informated object would be transformed according to stages of maturity of the overall process. Same could be argued for artefacts from category "c"-if e.g. the object of negotiation would be an informatable entity, the outcome of the negotiation could be an informated artefact - such as e.g. a passed law, or a signed deal.

The prevailing view amongst digital government scholars is that the nuts and bolts of governance (predominantly: public administration) is the handling of information along processes - such is e.g. the premise of Lenk (2012), Scholl and Klischewski (2007), Yildiz (2007), to name but a few. Such premise per se is not incorrect; however, from a perspective of informatability, it renders the problem of governance informating into a wicked one.

Wicked problems, according to Rittel (West Churchman 1967), are such problems in science, which cannot be solved in their entirety. Science, thus, can merely "tame their growl", or address a small part of them, rather than provide a clear explanation of their extent, or provide a solution. If governance informatization is attempted from the premise of governance being about handling information, the objective of governance informatization becomes the aim to informate the perpetually-transforming myriads of heterogeneous artefacts, which are handled by uncountable governance bureaus, institutions, and stakeholders of the system-of-systems that makes up the society. Taking the 
findings of Lenk (2012) and Paulin (2015) into consideration however, this objective would be rendered impossible to reach-governance informatization would thus become a dead end.

\section{In Search of the Atoms ${ }^{1}$}

This paper defined governance as the provision of nonmarket social functions in the public domain. The set of modern governance agents whose objective is to provide social functions to lesser or larger parts of the society, is so vast and complex that a concise overview of its extent and formal inter-agent relations perhaps might not feasibly be established. Unlike pieces of visual art, at whose core lie brush strokes, which easily can be informated, or computer reservation systems whose core represent informated travel tickets and available seats, the core of governance agents is harder to determine. The question in the process of informating the core however remains the same: "what are the informatable artefacts that need to be controlled to determine the system's outbound behaviour or representation?"

Thus, the question is not "what do we want a system to be", but rather, "how do we want to control it" - the ultimate objective of informating an artefact lies in the optimization of its control, in its consequent adjustability and interactivity. The informated scientific article's added value lies in its ability to be controlled in more powerful ways than its hand-typed legacy version was decades ago. The same is true for the informated credit transfer, informated airplane ticket, or the informated industrial plant. Likewise, the key to informating governance lies in its ability to be controlled in more powerful ways, and consequently optimized, rather than in the refactoring of its internal affairs.

In governance, the pro-forma content of the provided social functions is often of minor importance in comparison to the choice of individuals who deliver it. Downs (1967) for example argues that the survival of individual bureaus depends on being exempt from the public's antipathy-hence, bureaus survive for being tolerated, not for being needed or wanted. Thus, provided social functions are born out of the possibility for their existence, which does not imply crucially a rational need.

Quality, cost, and other parameters of the individual functions of government are hence determined by the personal characteristics of human agents who provide them. Thus, it is the personal qualities of judges who determine the outbound performance of the court, the charisma and devotion of teachers is what determines the quality of a school's output, the personal integrity and work ethic is what distinguishes a respectable public official from a corrupt and sluggish one, and the politician's worldliness and experiences are what separates the statesman from the short-sighted bigwig.

Controlling behaviour of governance is thus a matter of empowering individuals (or bureaus/institutions, respectively) to assume the respective status of power on all levels of governance. Giving and taking away power, as well as regulating the flow of public resources to a particular governance body are the core-most levers to control and adjust the social functions provided by such.

\footnotetext{
${ }^{1}$ The atomos, (Greek for "uncuttable"), refers to elements of a system that are not further dividable ("Ancient Atomism" 2005).
} 
Jellinek (1905) described the society as a system of subjective public rights. The core factor in this system is the jural status of the individual, which is a variable that defines the quality and extent of an individual's relation towards the society. The result is the model of a system consisting of simple and concise, yet incredibly powerful atomic relations, which determine the jural eligibilities of the individual in the relation to the society as a whole.

A third pillar for understanding the atoms of governance is provided by Hohfeld's theory of rights (Hohfeld 1920). Hohfeld's treatise elaborates on four categories of jural relations between individuals - namely claims, liberties, authorities, and immunities.

Combining the theories of Jellinek, Hohfeld, and Downs, we can construct a generalized and timeless model of governance: Social functions which are the claimed objectives of Downs' bureaus (e.g. the court's objective to solve disputes), are provided by individuals whose jural status enables them to do so (e.g. judges whose status enables them to issue rulings), while their power (e.g. the relevance of a court's rulings), entitlement to the social position (e.g. the judge being entitled to a title, public honour, and protection), and resources required to conduct them (e.g. the court's budget as a share of the national budget), base on the constraints of Hohfeld's jural rights.

More complex systems, such as hierarchies of checks-and-balances, collaborative decision-making, voting, etc., can then be modelled by means of atomic components provided by these three pillars. Such modelling does not conflict with other views (like, e.g. the view of the systems theory), as it is not focusing on the level of the concrete systems or their intrinsic processes, but purely on the factors that enable such systems on the atomic (i.e., not further dividable) level.

By informating these atomic components, optimization of governance by means of ICTs becomes hypothetically possible. The basic vision of e-governance research, i.e. the utilization of technology to make governance better, more transparent, more accountable, more participative, etc. can thus be approached by means of a lever composed of the power to control the jural status of individuals and bureaus entrusted with social function provision. The objective of governance informatization thus shifts away from researching technology that would hopefully make existing bureaus' social functions ambiguously "better", and focuses on designing an effective lever that would enable the control over latter. The premise thus becomes that control over social functions, their quality, necessity, and cost, could be established and informated, and that based on thus informated foundation, governance transformation could occur.

\section{Informating Governance}

In previous section, atomic components that are of crucial relevance to governance were narrowed down to a system of individuals who, due to their particular position within the society, provide their individual contributions to more complex social functions. Within the academic environment for example, the quality of teaching which students experience, is determined by the quality, charisma and devotion of the teaching faculty, while the quality, charisma, and devotion of latter will depend on satisfaction with their working conditions, their career perspectives, job security, private life, etc. While no technology will ever transform a bad teacher (or a bad judge, or a corrupt 
official) into a good one, technology can enable students to transform the way their academic curriculum is conducted or how their degrees are obtained.

On the atomic level, the challenge thus boils down to informating and controlling jural eligibilities, whereby each eligibility is determined by answering the "PAC $\mathrm{T}_{\mathrm{T}}$ " question "is person $P$ eligible to action $A$ in context $C_{T}$ ?", whereby context $C_{T}$ is the constantly evolving environment (hence " $\mathrm{T}$ " for time), and action $A$ is the desired status change of someone's jural status. Pioneering research in this regard has been conducted by Paulin (Paulin and Welzer 2013; Paulin 2013, 2014, 2012b), who elaborated a theoretical model for such informatization of jural eligibilities.

Paulin's approach to making jural eligibilities computable however does not informate eligibilities in form of informated Hohfeldian relations; neither does it informate the Jellinekian jural status. Rather, the system of determining eligibilities bases on a network of registries, which store information in form of fiat semantics, i.e. information, which has a meaning that is not explicitly stored in the system. (Chinese characters likewise deploy fiat semantics, which unfold meaning based on contemporary conventions, which allows for dynamic adaptation to future extensions/modifications.) The independence of the system behaviour from the semantics is what makes this system assumingly universal and applicable to hypothetically any governance relation imaginable.

The result can best be described as a blank-slate marriage between e-government at a fully transactional-state maturity level (thus, everyone can themselves interact with the system to influence their jural status and -relations to others) (Paulin 2013), open government data (access to the thus stored data is enabled by design) (Paulin 2013), liquid-democratic empowerment and liquid-democratic rule-creation and-modification (Paulin 2014). The data stored within the system is governed by regulations, which regulate under which conditions a particular person can read/write/modify a particular data field, whereby these regulations rely on constellations of existing data stored in the system in order to regulate access - thus, through properly changing the set of data stored in the system, one changes the level of access granted by the system itself. The regulations then, are themselves data stored in the system, which means that they can be, like all other data, also read/written/modified under the same principles, i.e. also access to them is regulated by the very same regulations and thus, they can be changed to globally change the regime of read-write access to the data. Latter is crucial to enable collaborative setting of regulations (such as e.g. through liquid-democratic principles), which allows a society to directly enact new regulations (or regulation changes) within the core system itself. Since access to data is regulated on its atomic level (i.e. on the level of each data field itself), a custom fine-grained-access-control system with an embedded regulation-policy change mechanism has been proposed (Paulin 2012b) to cater for this functionality.

Both the Jellinekian jural status and the Hohfeldian jural relations between individuals are calculated from the stored data in the form of $\mathrm{PAC}_{\mathrm{T}}$ questions. What is informated in Paulin's approach, is the format of regulations, which govern access to the data, as well as the structure of the request and response messages for the interaction with the system. The proposed approach to querying data is to use existing SQL technology, which is a well-established system for creating, storing, and querying data.

The feasibility of this approach to governance informatization crucially relies on three factors - the informatability of identity, to provide non-repudiable identification 
towards the system, the informatability of the jural status, which is required to control one's eligibilities towards-, and status within the society, and the informatability of collaborative decision making, which is required to control the atomic factors (the eligibilities, the status, the regulations) in a direct, collaborative manner. Below subsections discuss the constraints of each of these three factors.

\section{Informating Identity}

An informated identity is crucial for any kind of authentication towards systems for informated governance. The modern digital identity-i.e. functionality for identification, authentication, and signing, as of today is, due to manifold incompatibilities (Paulin 2012a), a challenging topic on its own and requires further focus to reach a state in which a clear and sustainable digital representation of identity can be achieved. Informated identity is required both at the level of stored data-where a representation of it is stored as a reference to the identity-holder, as well as on the level of authenticity of communication, where the identity-holder not only non-repudiably signs the $\mathrm{PAC}_{\mathrm{T}}$ statement, but does it in such way, that its identity can be retrieved from the signature.

Although digital identity is today a well-established field of research and development, applying it in giant-scale informated governance implies new challenges: How, for example, would an individual receive its digital identity? Who could it change it? What would happen, if the informated identity would become compromised? How would be the entity providing identity? And, could there be many identity-providing entities?

Aside from the question how to represent identity, further challenges lie in finding how proxies could be utilized to act on behalf of subjects. Proxies would be crucial to enable advanced services, such as when $\mathrm{PAC}_{\mathrm{T}}$ statements are routed through many complex instances, or when the requesting individual is not capable (too old/young, deceased, handicapped, etc.) to act on its own behalf.

From a point of view of its informatability, identity can be considered a successfully closed chapter. Taking the implications of its long-term, giant-scale, real-world applicability into account however, identity yet requires much attention to cover aspects, which lie only partly in the domain of technology design.

\section{Informating Eligibilities}

Determining eligibilities implies the existence of the external recipient, who knows how to interpret the response to the $\mathrm{PAC}_{\mathrm{T}}$ statement. This recipient may be a human actor, who derives the legitimacy of its real-world action from the received response. The response will be influenced by the identity of the requester and the context of the request. The identity of the requester implies (but not explicitly conveys) its jural status, which further depends on the context. The context of governance, then, is a perpetually unpredictably morphing system of environment rules and inter-stakeholder relations, which fills political and jurisdictional spaces, interflows and overflows the borders of non-tangible territories.

Most importantly however, the constraints of the context are not storable in monolithic documents, but are rather derived from a multitude of co-existing regulations, which act cascadingly (think of the system of laws, bylaws, court cases, etc.). The 
individual regulation can be designed and stored as an informated document (Paulin for example does so by means of a specific XML format and a system of cascading SQL queries (Paulin 2012b)), however it cannot be foreseen which other such documents will co-exist at a specific point in time. Furthermore, it is not possible to predict which set of regulations will apply to a concrete $\mathrm{PAC}_{\mathrm{T}}$ request, as the set of applicable regulations will be further dependent on the content of the $\mathrm{PAC}_{\mathrm{T}}$ request itself. This overall non-foreseeability of the concrete context's details is a crucial factor why the context as a whole cannot be informated as a holistic system - the tempting idea of government as a "god class" (Dierking 2010), "platform" (O'Reilly 2010), or perfect "one-stop-shop" (Wimmer 2002)—all these ideas are shared by both e-government as well as Smart City research, thus vanishes into thin air.

Aside from the informatable structure for describing $\mathrm{PAC}_{\mathrm{T}}$ statements, constellations of stored data can be considered as ad-hoc informated artefacts; "constellation" here denotes the relation between individual data tuples, which are stored within the relational data collection. Such constellation would for example be the relation between an identity identifier, a land parcel identifier, and an attribute denoting the identity's entitlement to the land parcel at stake. The relation between the tuples however can only be an implied one, which again, as argued above, requires a recipient to understand its meaning. This is crucial, as the relation as such does not constitute a concrete context-immune eligibility — on the contrary, the eligibility relies on the context, which implies the extent of rights.

Controlling the context and thus the eligibilities is a matter of designing and enacting on the one hand the regulations which apply to the context, and on the other designing constellations which act as meaningful templates for $\mathrm{PAC}_{\mathrm{T}}$ requests - to answer e.g. questions such as "is person $P$ currently a teacher entitled to fail student $S$ at course C?"

\section{Collaborative Decision-Making}

Governance without collaborative decision-making is impossible to imagine - taking into account, naturally, that collaborative decision-making does not mean only direct/ base-democratic decision-making, but rather refers to any kind of decisions taken by collective bodies, such as the board of directors, or any other steering committee. Few are the cases where a single man would make a public-sphere decision singlehandedly, even less a decision that would influence the jural context.

Enabling collaborative decision-making by means of controlling eligibilities is thus a crucial prerequisite for a system of informated governance. It enables the collaborative empowerment of individuals (by creating data, which influences their jural status), the collaborative provision of funding (by, again, generating data that entitles individuals to access public funds), as well as the collaborative control over regulations.

As demonstrated in (Paulin 2014), collaborative decision-making can be catered for by means of controlling eligibilities. The guiding idea here is that a collaborative decision can be enacted provided that the context has been shaped favourably for the enactment to happen. The shaping of the context occurs for example, if a majority of members of a committee (or parliament, or voting base, or participating voters, etc.) has declared their support for the enactment at stake - a dedicated regulation, which governs the enactment then can take such implicit majority into account for allowing 
the enactment to take place. This way collaborative decisions can be made, which in the real-world for example empower a citizen to become major of a town "elected" by the town's residents, or the president of a shareholder company "elected" by the shareholder assembly, or professor appointed by the dean of a faculty, based on the consensus of the curia. Likewise, regulations (like real-world laws or bylaws) can be collaboratively enacted or modified.

\section{The Informated Smart City}

Let us imagine how informated governance enables the Smart City: Franck is a governance informatization student from Maribor, who moves to Vienna for his master studies; this study program is a sub-branch of informatics - it gives him the skills required to develop advanced software systems, with a special focus on mastering the core technology stack of informated governance. He has a car, but no flat, and no parking space. Franck is a digital native, and a subscriber to Utopia, a pan-European virtual community, which provides services to its clients to make their life easier.

Utopia provides a service layer of digital technologies, which provide advanced functionality for the interaction with the registries of jural relations on which Vienna's public sphere relies. There is no single public-domain-related eligibility that would not be part of the ubiquitous registries: the mandates of contractors who maintain the city infrastructure are awarded through the registries, one's eligibility to live in a municipal apartment is stored in the registries, the city government is empowered through the registries, and even when Franck purchases a metro ticket, he does so by acquiring the desired eligibility through the registries.

Also, Franck's matriculation with the university was realized through the registries. Franck used Utopia's intuitive Life-Management (LM) software suite to switch from Maribor to Vienna; he did learn in school already how to script against the registries, but it is simply way more convenient to use Utopia's technology to interact with the public domain.

The open de-facto standards, which most societies embrace to informate their public services, made it easy for commercial providers like Utopia and the open source community to provide tools that make one's life easier. Utopia is simply cool to use and updates itself to accommodate to one's life situation and geographic context. This allows Franck to use the same app as he used while in Maribor to pay for the public transport, to interact with the university, and to manage his rental affairs. Technically speaking, the used protocols and standards are the same; more or less only the registries' locations and broadness of the features differ from one city to another.

Utopia manages also Franck's finances - he uses the app to pay and to handle his monthly bills. Utopia's billing model is social - every user pays one percent of its net income - also this agreement is enshrined in the registries, as agreements are protected by the system only once they are stored in the registries. Franck does not transfer money for his subscription to Utopia, neither does Utopia credit his account; rather, from all of Franck's incoming transactions, Utopia has the eligibility to use its $1 \%$. Also taxation is handled this way: a small percentage of the rent Franck pays, of the goods he buys, and the income he receives is "locked" for the disposal of the community. 
Public domain affairs are handled through liquid democracy, which allows each community member to co-decide on the governance of the city. When the system was introduced, the city used to have for a while still a town council, which however dismantled itself once the citizens abolished the attendance fees and privileges of the councilors.

Since the transition to full liquid democracy, political activities have shifted from the periodic rally for the town council to competing service providers. This enabled citizen to transfer the mandate for the public transport system to alternative operators, who reduced the transport fees and upgraded the network capacities. The closer proximity to community funds encouraged citizens to take grassroots initiative and to engage stronger in public discourse. No longer did they give their vote away for a couple of years - suddenly their political power mattered.

But, back to Franck: Utopia's LM will aid him in his search for an apartment. He might even find an apartment provided by the Utopia community itself; the same applies for the parking space and other services of social function providers Franck might require during his lifetime. The clear standardization and equal access to the system gave birth to many communities like Utopia who provide advanced convenience services on a commercial basis; Utopia, though, is the dominant one.

Utopia, everybody agrees, has deserved its prime position. It was the first big player in this multitrillion Euro market, and it did a good job in transiting the field from theory into praxis, investing into technology and standardization, and supporting science and universities to kick-start the ecosystem of developers needed to informate governance provision. It promised an efficient alternative to corrupt, expensive, and slow bureaucracies, and it delivered. It followed a long-term vision of sustainable global expansion, and with quality, efficiency and sustainability it gained the trust of its members, who gladly contribute to its success as customers, users, and developers.

But, the ecosystem is not only Utopia; each day new ideas emerge and new startups and visionaries aim for their place in the ecosystem. The open standards and the genericity of the technology stack prevent monopolization and exclusion of access to the governance technology. Perhaps, Franck will use his knowledge to build the next Utopia?

\section{Conclusion}

This paper summarized key concepts of governance informatization and provided a vision of its applicability. The focus of the paper was on addressing two research questions: R1 was about finding the atomic factors of governance, while R2 was interested in whether such atomic factors can be informated.

R1 was answered by identifying governance as a system of providers of heterogeneous social functions, which are delivered by individual agents empowered to do so. Within this system Jellinek's concept of the jural status and Hohfeld's system of jural relations have been identified as the atomic artefacts which can be used to model hypothetically any governance system. The atomic elements thus are the jural status, the jural relation, and the identity, which denotes the individual subject.

$\mathrm{R} 2$ revealed that from the atomic elements revealed through R1 only identity could be directly informated. The jural status and jural relations cannot be feasibly informated 
directly due to their recursive interdependency on the jural context, which at the same time determines the extent of the jural status and relations, while being itself determined by their extent. It was found however that potential for transforming governance by means of ICT nonetheless is provided, if indirect informating is taking into consideration, whereby the jural status, as well as the jural relations are calculated ad hoc when required.

The thus gained knowledge contributes to understanding core principles for developing sustainable core technology for governance in general, and thus including urban governance specifically. The creation and steering of the manifold social functions within such ecosystems thus becomes comprehensibly informatable, enabling disruptive innovation beyond legacy approaches.

\section{Acknowledgments Open access funding provided by TU Wien (TUW).}

Open Access This article is distributed under the terms of the Creative Commons Attribution 4.0 International License (http://creativecommons.org/licenses/by/4.0/), which permits unrestricted use, distribution, and reproduction in any medium, provided you give appropriate credit to the original author(s) and the source, provide a link to the Creative Commons license, and indicate if changes were made.

\section{References}

Ancient Atomism. (2005). Stanford Encyclopedia of Philosophy. http://plato.stanford.edu/archives/fall2008/ entries/atomism-ancient/.

Anthopoulos, L. (2015) “Defining Smart City Architecture for Sustainability." In Proceedings of the 14th IFIP Electronic Government (EGOV) and 7th Electronic Participation (ePart) Conference 2015. Presented at the14th IFIP Electronic Government and 7th Electronic Participation Conference 2015, IOS Press. Thessaloniki, Greece, pp. 140-47. doi:10.3233/978-1-61499-570-8-140

Anthopoulos, L., \& Fitsilis, P. (2013). Using classification and roadmapping techniques for Smart City viability's realization. Electronic Journal of E-Government, 11(1), 326-36.

Bevir, M. (2009). Key Concepts in Governance, SAGE key concepts. Los Angeles, London: SAGE.

Dierking, H. (2010). Engineering good government. In L. Daniel \& R. Laurel (Eds.), Open governmentcollaboration, transparency, and participation in practice (pp. 71-81).

Downs, A. (1967). Inside Bureaucracy. A Rand Corporation Research Study. Boston, Mass.: Little, Brown.

Hevner, A. R., March, S. T., Park, J., \& Ram, S. (2004). Design science in information systems research. Management Information Systems Quarterly, 28(1), 6.

Hohfeld, W. N. (1920). Fundamental Legal Conceptions as Applied in Judicial Reasoning: And Other Legal Essays. New Haven: Yale University Press. https://archive.org/details/fundamentallegal00hohfuoft.

Jellinek, G. (1905). System Der Subjektiven öffentlichen Rechte [System of Subjective Public Rights]. JCB Mohr (P. Siebeck).

Lenk, K. (2012). The nuts and bolts of administrative action in an information age. In I. Snellen, M. Thaens, \& W. van de Donk (Eds.), Public administration in the information age: revisited (pp. 221-34). Amsterdam: Ios Press.

O'Reilly, T. (2010). Government as a platform. In L. Daniel \& R. Laurel (Eds.), Open governmentcollaboration, transparency, and participation in practice (pp. 11-39).

Paulin, A. (2012a). "Status and Outlook on Electronic Identity in Europe: The Case of Austria." In Electronic Government and Electronic Participation: Joint Proceedings of Ongoing Research and Projects of IFIP EGOV and IFIP ePart 2012, edited by Marijn Janssen. Vol. 39. Schriftenreihe Informatik. Kristiansand: Trauner. http://research.apaulin.com/research/2012/egov2012-eid.

Paulin, A. (2012b). "Secure SQL Server - Enabling Secure Access to Remote Relational Data." arXiv: 1201.1081, January. http://arxiv.org/abs/1201.1081.

Paulin, A. (2013). "Towards Self-Service Government - A Study on the Computability of Legal Eligibilities." Journal of Universal Computer Science 19 (12): 1761-91. doi:10.3217/jucs-019-12-1761. 
Paulin, A. (2014). "Through Liquid Democracy to Sustainable Non-Bureaucratic Government - Harnessing the Power of ICTs for a Novel Form of Digital Government." eJournal of eDemocracy and Open Government 6 (2).

Paulin, A. (2015). "Twenty Years after the Hype: Is E-Government Doomed? Findings from Slovenia." International Journal of Public Administration in the Digital Age 2 (2): 1-21. doi:10.4018/ijpada. 2015040101

Paulin, A, \& Welzer, T. (2013). "A Universal System for Fair Non-Repudiable Certified E-Mail without a Trusted Third Party.” Computers \& Security. doi:10.1016/j.cose.2012.11.006.

Scholl, H. J., \& Klischewski, R. (2007). E-Government integration and interoperability: framing the research agenda. International Journal of Public Administration, 30(8-9), 889-920. doi:10.1080/ 01900690701402668.

Söderström, O., Paasche, T., \& Klauser, F. (2014). Smart cities as corporate storytelling. City, 18(3), 307-20. doi:10.1080/13604813.2014.906716.

West Churchman, C. (1967). "Guest Editorial: Wicked Problems.” Management Science 14 (4): B - 141 - B 146. doi:10.1287/mnsc.14.4.B141.

Wimmer, M. A. (2002). A European perspective towards online one-stop government: the eGOV project. Electronic Commerce Research and Applications, 1(1), 92-103. doi:10.1016/S1567-4223(02)00008-X.

Yildiz, M. (2007). E-Government research: reviewing the literature, limitations, and ways forward. Government Information Quarterly, 24(3), 646-65. doi:10.1016/j.giq.2007.01.002.

Zuboff, S. (1988). In the age of the smart machine: the future of work and power. New York: Basic Books. 